Retrospective Study

\title{
Comparison of Cervical Sagittal Alignment and Kinematics after Posterior Full-endoscopic Cervical Foraminotomy and Discectomy According to Preoperative Cervical Alignment
}

\author{
Samuel Won, BS ${ }^{1}$, Chi Heon Kim, MD, PhD ${ }^{2-4}$, Chun Kee Chung, MD, PhD ${ }^{2-5}$ \\ Yunhee Choi, $\mathrm{PhD}^{6}$, Sung Bae Park, MD ${ }^{2-4,7}$, Jung Hyeon Moon, MD², Won Heo, MD², \\ Sung-Mi Kim, $\mathrm{RN}^{3}$
}

From: ${ }^{1}$ Department of Medicine, Seoul National University College of Medicine; ${ }^{2}$ Department of Neurosurgery, Seoul National University College of Medicine; ${ }^{3}$ Department of Neurosurgery, Seoul National University

Hospital, Seoul, Korea; ${ }^{4}$ Clinical Research Institute, Seoul National University Hospital, Seoul, Korea; ${ }^{5}$ Department of Brain and Cognitive Sciences, Seoul National

University College of Natural Sciences, Seoul, Republic of Korea;

${ }^{6}$ Medical Research Collaborating

Center, Seoul National University College of Medicine, Seoul, Korea;

${ }^{7}$ Department of Neurosurgery, Seoul National University Boramae Hospital, Seoul, Korea

Address Correspondence: Chi Heon Kim, MD, PhD Department of Neurosurgery Seoul National University College of Medicine 101 Daehak-Ro, Jongno-gu Seoul, 110-744, South Korea E-mail: chiheonı@snu.ac.kr

Disclaimer: This work was supported by Grant No. 0420163070 (2016-1063) from the Seoul National University Hospital. The first author (CHK) is a consultant of Richard Wolf $\mathrm{GmbH}$. The other authors certifies that he or she, or a member of his or her immediate family, has no commercial association (i.e., consultancies, stock ownership, equity interest, patent/licensing arrangements, etc.) that might pose a conflict of interest in connection with the submitted manuscript.

Manuscript received: 06-20-2016 Revised manuscript received: 08-

$12-2016$

Accepted for publication: 08-22-2016

Free full manuscript: www.painphysicianjournal.com
Background: The progression of cervical kyphosis due to injury to the facet joints and musculature is a major concern for posterior foraminotomy especially for patients with cervical lordosis of less than $10^{\circ}$. However, cervical hypo-lordosis (cervical lordosis $<10^{\circ}$ ) may be improved with the alleviation of pain and muscle spasms, which corresponds with the disappearance of a positive Spurling's test. When surgery is necessary, the spontaneous recovery of cervical curvature may be minimally offset using minimally invasive surgical techniques, such as posterior percutaneous endoscopic cervical foraminotomy (P-PECF).

Objectives: The primary objective was to compare the changes in cervical kinematics between patients with cervical lordosis $\left(\geq 10^{\circ}\right.$, group I) and hypo-lordosis $\left(<10^{\circ}\right.$, group II) after P-PECF.

Study Design: This study was a retrospective nested case-control study with the IRB No. H-1210-078-434

Setting: University Medical Center, Seoul, Korea.

Methods: P-PECFs were performed for patients with a radiculopathy due to single-level unilateral cervical foraminal soft-disc herniations or foraminal stenosis with minimal degeneration of the disc/facet joints and a positive Spurling's test. A retrospective nested case-control study was performed for 23 patients with cervical lordosis of $\geq 10^{\circ}$ (group I; M:F = 15:8; age, $52.3 \pm$ 9.8 years) and 23 patients with cervical lordosis of $<10^{\circ}$ (group $\|$; $M: F=15: 8$; age, $46.3 \pm 12.7$ years). P-PECFs were performed using the methods previously reported, and all patients were discharged the next day without limitations on neck motion. The patients were followed at one, 3, 6, and 12 months postoperatively and yearly thereafter. The follow-up period was 25.8 \pm 19.6 months. Clinical outcomes were assessed using the visual analogue pain score of arms. The cervical angles (C2-7, tangential method) were measured on neutral (CA), flexion (CAF), and extension (CAE) lateral radiographs, and range of motion (C-ROM) was calculated by conducting a radiological analysis. A linear mixed model was used to assess the linearity of the changes in cervical curvatures during the postoperative 12 months between the groups.

Results: Significant reductions in arm pain and negative results on Spurling's test were initially achieved in 21/23 patients in group I and in 23/23 patients in group II with means of $1.7 \pm 0.31$ months and $1.09 \pm 0.09$ months, respectively. Using the mixed effect models, the interactions between group and time were significant for the CA $(P=0.004), C A E(P<0.001)$, and C-ROM $(P<0.001)$ but not the CAF $(P=0.392)$. The CA (adjusted- $P<0.001), C A E$ (adjusted- $P<0.001)$, and C-ROM (adjusted- $P=0.046$ ) exhibited significant between-group differences at the preoperation. However, during the follow-up, these parameters were significantly changed in group II, especially during the postoperative 3 months. The CA, CAE, and C-ROM changed by $-11.73^{\circ}$, $-19.87^{\circ}$, and $20.32^{\circ}$, respectively. Postoperatively, $17 / 23$ patients in group II and 22/23 patients in group I exhibited cervical lordosis of $\geq 10^{\circ}$.

Limitations: This study was retrospective in design, and the inherent selection bias and limited statistical power should be considered. 
Conclusions: Cervical hypo-lordosis less than $10^{\circ}$ may not be a contra-indication for P-PECF when the change of cervical curvature is not a structural change. A larger study is necessary to identify prognostic factors.

Key words: Alignment, cervical vertebrae, disc, percutaneous, endoscopes, biomechanical phenomena, surgery, lordosis, kyphosis

Pain Physician 2017; 20:77-87

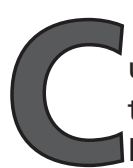

urrently, there are various options for the treatment of cervical radiculopathy due to lateral soft disc herniation or foraminal stenosis (1-8). Analgesic medication, epidural steroid injection, and/or other procedures are the initial treatments of choice, but surgery may be considered when such conservative options are not effective $(7,8)$. Anterior cervical discectomy and fusion (ACDF) or artificial disc replacement are common surgical options, but these methods may have problems such as limitations of neck motion, dysphagia, hoarseness, adjacent segment degeneration, heterotopic ossification, and mechanical failure (9-11). Considering the maintenance of cervical motion, the posterior cervical foraminotomy technique may be an attractive option for managing single-level spondylotic radiculopathy in the absence of central cord compression (3). However, progression to the cervical kyphosis or loss of the lordosis due to injuries on the facet joint and musculature have been major concerns related to posterior foraminotomy, especially for patients with cervical lordosis of less than $10^{\circ}(2,3)$. With recent advances in spinal endoscopic surgical techniques, posterior percutaneous endoscopic cervical foraminotomy (P-PECF) has demonstrated acceptable outcomes (5-7,12-14). However, the application of P-PECF for patients with decreased cervical lordosis remains controversial because of the similarity of the surgical approach $(2,3,6)$. However, cervical hypo-lordosis may be spontaneously recovered with the alleviation of pain and muscle spasms, which corresponds with the disappearance of a positive Spurling's test $(6,15)$. The violations to the muscle and facet joint may be minimized with P-PECF, and the spontaneous recovery of cervical curvature may be minimally offset using P-PECF $(6,13)$. The primary purpose of the present study was to compare the changes in cervical kinematics between patients with cervical lordosis $\left(\geq 10^{\circ}\right)$ and hypo-lordosis $\left(<10^{\circ}\right)$ after P-PECF. The secondary objectives were to compare the clinical outcomes and changes in cervical sagittal alignments.

\section{Methods}

\section{Patients}

After obtaining permission from the Institutional Review Board (H-1210-078-434), the medical records of 71 consecutive patients who underwent posterior percutaneous endoscopic cervical foraminotomies and discectomies (P-PECF) between June 2010 and September 2015 were retrospectively reviewed. P-PECFs were performed for patients whose main presentations were radicular pain due to single-level cervical foraminal soft-disc herniations or foraminal stenoses. All patients had minimal disc and facet joint degeneration and exhibited a positive Spurling's test $(5,6,15,16)$. The degree of disc degeneration was evaluated with T2weighted sagittal magnetic resonance imaging (MRI) as described by Pfirrmann et al (17), and grades of I, II, and III (inhomogeneous structure of the disc with an intermediate, gray signal intensity with a preserved or slightly decreased disc height) were considered to be acceptable for posterior-PECF (4-6). P-PECF was not indicated for patients with pure neck pain, central stenosis/ myelopathy, symptomatic central disc herniation, gross cervical instability, moderate to severe facet degeneration (joint space narrowing, facet hypertrophy or large osteophyte) (18), or ossification of the posterior longitudinal ligament $(5,6,19)$.

Preoperatively, MRI) and plain radiographs were obtained. Every patient completed questionnaires to determine their neck disability index (NDI, out of 50) (20) and visual analogue pain scores for the neck (Neck-VAS, out of 10) and arm (Arm-VAS, out of 10). The P-PECF was performed under general anesthesia, and all patients were discharged the next day. None of the patients had to use a neck collar, and free neck motion was encouraged $(5,6)$. Regarding the postoperative follow-up, the patients were scheduled to visit the outpatient clinic at one, 3, 6, and 12 months, and yearly thereafter. At each visit, the patients were asked to complete the same questionnaires to describe their 
symptoms. Plain radiographs including dynamic images were also obtained at the 3-, 6-, 12-, and 24-month postoperative visits $(5,6)$.

A retrospective study was designed to compare the outcomes after P-PECF between the patients with cervical lordosis of $\geq 10^{\circ}$ (group I) and the patients with cervical lordosis of $<10^{\circ}$ (group II). The clinical outcomes were evaluated in all 71 patients through reviews of medical records and telephone contacts. Because this research was performed retrospectively, not all the patients completed x-ray imaging at every follow-up, and 46 of the 71 patients who had at least 2 followup images during the postoperative 12 months were analyzed in this study. The characteristics of patients are described in Table 1.

\section{Surgical Techniques}

Surgical techniques were similar to those previously reported $(5,6,12,13)$. All of the operations were performed under general anesthesia with the patient in a prone position using 3-point skeletal pin fixation devices with a table-mounted Mayfield ${ }^{\circledR}$ holder (Intergra, New Jersey, USA) or in craniocervical traction using a Gardner-Wells tong skeletal fixation system $(5,6)$. After a skin incision of $8 \mathrm{~mm}$ was made above the medial junction of the inferior and superior facet joint ( $V$-point), which was identified with an intraoperative orthogonal fluoroscopic image, the obturator $(6.9 \mathrm{~mm}$ outer diameter), working channel $(8.0 \mathrm{~mm}$ outer diameter), and endoscope (4.1 mm working channel, Vertebris $®$, Richard Wolf $\mathrm{GmbH}$, Knittlingen, Germany) were introduced $(5,6,16)$. The entire operation was performed under visual control and continuous irrigation with normal saline, which was hung approximately $1.5 \mathrm{~m}$ above the patient $(5,6,12,13,16)$. After the clearing out of the soft tissue around the V-point, the descending lamina, ascending lamina, and facet joint were serially drilled out. The size of the bony drilling was dependent on the size and location of the herniated disc material and the extent of stenosis, and it was usually within a 3-4 $\mathrm{mm}$ radius around the $\mathrm{V}$-point for soft disc herniations and $5-6 \mathrm{~mm}$ for foraminal stenoses $(5,6,16)$. Ruptured fragments of the disc were removed from the axillary or shoulders of the nerve roots in 30/46 patients. Decompression of the nerve root was confirmed by both visualization and palpation from points either inferior or superior to the nerve root $(5,6,16)$. After the operation, a closed suction drain was inserted through the working channel in cases of epidural bleeding, and the drain was removed the next day $(5,6,16)$.
Table 1. Characteristics of patients.

\begin{tabular}{||l|c|c|c|c||}
\hline & $\begin{array}{c}\text { Group I } \\
(\mathbf{n}=\mathbf{2 3})\end{array}$ & $\begin{array}{c}\text { Group II } \\
(\mathbf{n = 2 3 )}\end{array}$ & Total & P-value* \\
\hline Age & $\begin{array}{c}52.3 \pm 9.8 \\
(31-68)\end{array}$ & $\begin{array}{c}46.3 \pm 12.7 \\
(26-70)\end{array}$ & $\begin{array}{c}49.3 \pm 11.6 \\
(26-70)\end{array}$ & 0.10 \\
\hline Sex (M:F) & $15: 8$ & $15: 8$ & $30: 16$ & 1.00 \\
\hline Level & 3 & 2 & 5 & \\
\hline C4-5 & 6 & 6 & 12 & \\
\hline C5-6 & 11 & 14 & 25 & \\
\hline C6-7 & 3 & 1 & 4 & \\
\hline C7-T1 & $7: 16$ & $11: 12$ & $18: 28$ & 0.23 \\
\hline Side (R:L) & 15 & 15 & 30 & 1.00 \\
\hline $\begin{array}{l}\text { Soft disc } \\
\text { herniation }\end{array}$ & 0 & 8 & 8 & \\
\hline Kyphosis & $26.1 \pm 19.4$ & $\begin{array}{c}26.6 \pm 20.2 \\
(3-61)\end{array}$ & $\begin{array}{c}25.8 \pm 19.6 \\
(3-62)\end{array}$ & 0.99 \\
\hline Clinical F/U & $(3-62)$ & $\begin{array}{c}13.5 \pm 14.1 \\
(3-55)\end{array}$ & 0.43 \\
\hline $\begin{array}{l}\text { Radiological } \\
\text { F/U }\end{array}$ & $\begin{array}{c}12.3 \pm 13.8 \\
(3-55)\end{array}$ & $\begin{array}{c}14.6 \pm 14.6 \\
(3-53)\end{array}$ & \multicolumn{2}{|l|}{} \\
\hline
\end{tabular}

${ }^{*}$ comparison between group I and II

\section{Radiological Evaluation}

Patients were subjected to x-rays in the neutral, flexion, and extension neck postures. The patients were asked to stand and look straight ahead for the neutral position and to flex and extend neck to the extent they could tolerate for the flexion and extension $x$-rays $(5,6,21)$. The same protocol was followed for all preoperative and postoperative imaging. To measure cervical curvature, we used cervical angles between C2 and $\mathrm{C7}$ using the tangential method (CA) and using the segmental Cobb angle at the operative level (SA) (Fig. 1). These radiological parameters were measured on the neutral, flexion, and extension lateral x-ray images that were taken at the preoperative and follow-up visits (3, 6, and 12 months). Negative angles indicated lordosis, and positive angles indicated kyphosis. Cervical spine range of motion (C-ROM) was calculated by subtracting the cervical angle during extension (CAE) from the cervical angle during flexion (CAF), while the ROM of the operated segment (S-ROM) was similarly calculated by subtracting the segmental angle during extension (SAE) from the segmental angle during flexion (SAF). The cervical curvatures of the patients were classified as lordosis $\left(C A \leq-10^{\circ}\right)$, hypo-lordosis $\left(-10^{\circ}-0^{\circ}\right)$, or kyphosis $\left(C A>0^{\circ}\right)$. To assess the cervical sagittal alignments, the $\mathrm{C} 2$ sagittal vertical axes 


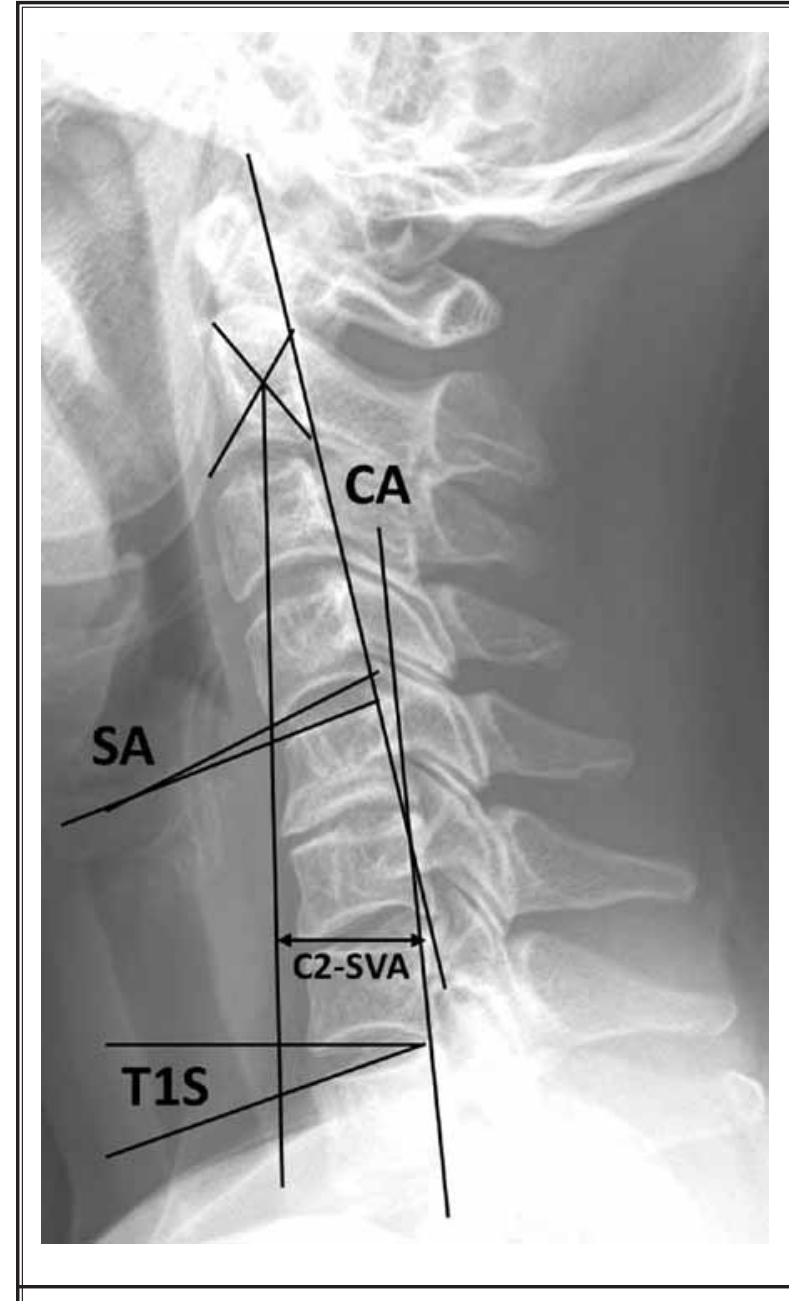

Fig. 1. Radiological measurements. The cervical angle (CA) was measured from $C 2$ to $C 7$ using the tangential method. The segmental angle $(S A)$ was measured from the superior endplate to the inferior endplate of the cephalic and caudal vertebra using Cobb's method. Similarly, CA and $S A$ were measured using flexion ( $C A F$ and $S A F$ ) and extension (CAE and $S A E$ ) $x$-rays. The T1 slope angle (T1S) was measured between the horizontal line and the extension line along superior the endplate of T1. The C2 plumb line was drawn from the center of C2. The C2-SVA was measured as the shortest perpendicular distance to the posterior superior corner of $C 7$.

(C2-SVA) and T1 slope angles (T1Ss) were measured (21-26) (Fig. 1). The C2-SVA and the mismatch between the T1S and CA (T1S-CA; T1S + CA) were used to evaluate the sagittal balance $(25,27)$. A researcher who was blinded to the patient information completed all the radiological measurements. The measurements and the analysis were performed with $150 \%$ magnified views using measuring tools in the image archiving and communication software (Marosis, version 5483, Infinitt Healthcare, Seoul, Korea), which was run in a Microsoft Windows environment (Microsoft Corp., Redmond, WA, USA) (28).

\section{Statistical Analysis}

The patients were combined into groups I (CA $\left.\leq-10^{\circ} ; n=23\right)$ and II (CA $\left.>-10^{\circ} ; n=23\right)$. Radiological and clinical outcomes were compared between group I and group II. Normalities of the continuous variables were checked using the Shapiro-Wilk test and Q-Q plots. Mann-Whitney $U$ tests (or t-tests) and Chi-square tests were used to compare between groups. The minimal clinically important difference (MCID) of the Arm-VAS, Neck-VAS, and NDI values were set at 2.5, 2.5, and 7.5, respectively, in accordance with the previous literature (29). Clinically, both the disappearance of a positive Spurling's test and a decrease in the Arm-VAS of more than the MCID were considered successful outcomes. A Kaplan-Meier survival analysis and a Cox-regression analysis were performed to assess influences of cervical curvature on the Arm-VAS, Neck-VAS, and NDI. Linearity assumptions for the continuous variables (age, preoperative neck-VAS, and preoperative NDI) were examined using restricted cubic splines. The proportional hazard assumption was tested using the Cox proportional hazard model with an interaction term with time. A linear mixed-effect model, which represents correlation among repeated measures from a subject, was used to assess the longitudinal changes in the cervical curvatures (CA, CAF, CAE, and C-ROM), segmental curvatures (SA, SAF, SAE, and S-ROM), and sagittal balances (C2-SVA, and T1S-CA) during the postoperative 12 months. The fixed effects were group, time, the interaction between group and time, age, and gender, while the random effect was subjects. The post hoc analysis using a stepdown Bonferroni method was planned for the radiological outcomes with the significant interaction effects as follows: the time trend in each group, changes between the preoperation and post-operation time points $(3,6$, and 12 month) for the groups with significant time trends, and the group differences at each time point. Specifically, the adjusted mean changes during the first 3 months after the operation were estimated using the $99.5 \%$ confidence intervals using the mixed-effect model. All of the statistical analyses were performed using SAS (version 9.2, SAS Institute, Cary, NC, USA), and statistical significance was defined as $P<0.05$ (two-sided). 


\section{Results}

\section{Clinical Outcome}

The clinical outcomes are described in Table 2. All the clinical parameters were significantly decreased at the last follow-up without statistically significant differences between the groups. Successful outcomes were initially obtained in $21 / 23(91 \%)$ of the patients in group I and 23/23 $(100 \%)$ of the patients in group II after means of $1.7 \pm 0.31$ months (median one month; range, $1-3$ ) and $1.09 \pm 0.09$ months (median one month, range, 1 - 3), respectively, without differences between the groups ( $P=0.67$ ) (Fig. 2). Because the patients were followed at pre-determined time points, the improvements in arm pain were regarded to have occurred between one and 3 months after the surgeries (30). Age, gender, preoperative neck-VAS, preoperative NDI, and disease type (soft disc herniation vs. foraminal stenosis) were not significant predictive factors for the outcomes of the surgery $(P=0.77,0.84$, $0.99,0.60$, and 0.70 , respectively). During the follow-up period, arm pain remained significantly improved in most patients, but one patient in each group experienced recurrence of arm pain at postoperative 24 and 36 months. The patient in group I underwent revision P-PECF at C7-T1 at postoperative 28 months due to arm pain (7/10) and weakness in the hand (C8 radiculopathy). A recurred foraminal disc was removed with revision $\mathrm{P}-\mathrm{PECF}$, and the weakness and arm pain has since improved. The
Table 2. Clinical outcomes.

\begin{tabular}{|l|c|c|c|c|}
\hline & $\begin{array}{c}\text { Group I } \\
(\mathbf{n}=\mathbf{2 3})\end{array}$ & $\begin{array}{c}\text { Group II } \\
(\mathbf{n}=\mathbf{2 3})\end{array}$ & Total & $\boldsymbol{P}$-value* \\
\hline $\begin{array}{l}\text { NDI (preop) } \\
\text { Median (min, max) }\end{array}$ & $20(12,42)$ & $25(11,36)$ & $24.5(11,42)$ & 0.22 \\
\hline NDI (final) & $2(0,21)$ & $0(0,10)$ & $1(0,21)$ & 0.4 \\
\hline Neck-VAS (preop) & $5(0,9)$ & $6(0,10)$ & $6(0,10)$ & 0.24 \\
\hline Neck-VAS (final) & $0(0,7)$ & $0(0,6)$ & $0(0,7)$ & 0.98 \\
\hline Arm-VAS (preop) & $7(4,10)$ & $8(5,10)$ & $7(4,10)$ & 0.12 \\
\hline Arm-VAS (final) & $1(0,5)$ & $0(0,6)$ & $0(0,7)$ & 0.68 \\
\hline
\end{tabular}

*comparison between groups; Kruskall-Wallis test

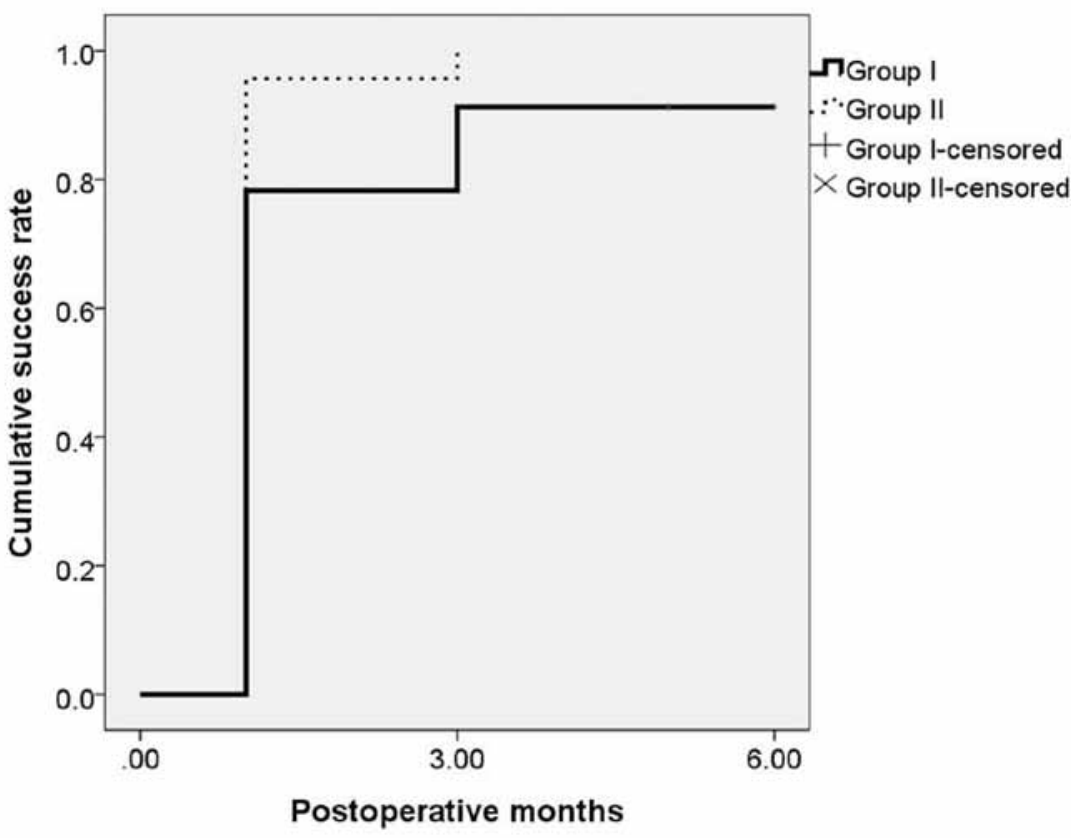

Fig. 2. Improvement of arm pain. Successful outcomes were initially obtained in 21/23 (91\%) of the patients in group I and 23/23 (100\%) of the patients in group II after means of $1.7 \pm 0.31$ months (median one month; range, $1-3$ ) and $1.09 \pm 0.09$ months (median one month, range, $1-3)$, respectively, without differences between the groups ( $P$ $=0.67)$.

other patient in group II received epidural injections, and the pain subsided during the remaining follow-up period (60 months). At the last follow-up, 20/23 $(87 \%)$ of the patients in group I and $23 / 23(100 \%)$ of the patients in group II exhibited successful outcomes.

The MCIDs of the NDIs were initially reached in $21 / 23(91 \%)$ of the patients in group I and $23 / 23(100 \%)$ of the patients in group II at means of $3.1 \pm 0.88$ months (median 2 months, range $1-12$ ) and $1.30 \pm 0.23$ months (median one month; range 1 - 6), respectively. Similarly, the MCIDs of the Neck-VASs were 
reached in $21 / 23(91 \%)$ of the patients in group I at a mean of $3.0 \pm 0.81$ months (median one month, range, $1-12)$ and in $23 / 23(100 \%)$ of the patients in group II at a mean of $2.91 \pm 0.79$ months (median one month; range, 1 - 12). The times for improvements in the NDIs and Neck-VASs were not different between the groups ( $P=0.37$ and 0.99 , respectively). During the follow-up period, aggravation of neck pain and NDI occurred in 3 patients ( 2 patients in group I and one patient in group II) at 24 months, 27 months, and 36 months, respectively. Two of these 3 patients experienced recurrence of combined arm pain as mentioned earlier. The neck pain, arm pain, and NDI were controlled with medication and physiotherapy with or without epidural injections in the 2 patients. As mentioned, reoperation was necessary in one patient in group $\mathrm{I}$.

\section{Radiological Outcomes}

Using the mixed effect models, the interactions between group and time were significant in CA ( $P$ $=0.004), \operatorname{CAE}(P<0.001)$, C-ROM $(P<0.001)$, SA $(P=$ $0.043), \operatorname{SAE}(P<0.001)$, and S-ROM $(P=0.014)$ with the exception of CAF $(P=0.392)$ and SAF $(P=0.513)$. The group differences were evaluated at each time. CA (adjusted- $P<0.001$ ), CAE (adjusted- $P<0.001$ ), C-ROM (adjusted- $P=0.046$ ), and SAE (adjusted- $P=0.031$ ) were significantly different between the groups at pre-oper-

Table 3. Preoperative radiological parameters.

\begin{tabular}{|l|c|c|c||}
\hline & Group I & Group II & Total \\
\hline CA & $-18.32 \pm 6.52$ & $-0.38 \pm 7.38$ & $-9.35 \pm 11.38$ \\
\hline CAF & $12.60 \pm 10.14$ & $19.39 \pm 10.31$ & $16.00 \pm 10.67$ \\
\hline CAE & $-28.35 \pm 7.69$ & $-11.71 \pm 13.42$ & $-20.03 \pm 13.70$ \\
\hline C-ROM & $40.70 \pm 12.71$ & $31.10 \pm 18.42$ & $35.90 \pm 16.38$ \\
\hline SA & $-2.65 \pm 5.23$ & $1.56 \pm 6.12$ & $-0.50 \pm 6.02$ \\
\hline SAF & $5.58 \pm 5.48$ & $6.58 \pm 5.42$ & $6.11 \pm 5.41$ \\
\hline SAE & $-3.57 \pm 4.43$ & $0.13 \pm 4.35$ & $-1.63 \pm 4.72$ \\
\hline S-ROM & $9.15 \pm 6.51$ & $6.45 \pm 4.97$ & $7.74 \pm 5.84$ \\
\hline T1S-CA & $7.10 \pm 6.30$ & $17.05 \pm 9.36$ & $12.30 \pm 9.41$ \\
\hline C2-SVA & $22.28 \pm 10.57$ & $29.28 \pm 12.61$ & $25.94 \pm 12.08$ \\
\hline
\end{tabular}

$\mathrm{CA}$, cervical angle; $\mathrm{CAF}$, cervical angle in flexion; $\mathrm{CAE}$, cervical angle in extension; C-ROM, range of motion of cervical curvature; SA, segmental angle; SAF, segmental angle in flexion; SAE, segmental angle in extension; S-ROM, range of motion of segmental curvature; T1S-CS, mismatch between $\mathrm{T} 1$ slope angle and cervical angle; C2-SVA, horizontal distance from $\mathrm{C} 2$ plumb line to $\mathrm{C} 7$. ation, but SA (adjusted- $P=0.142$ ) and S-ROM (adjusted$P=0.164$ ) were not statistically different (Table 3 ). Only CA was significantly different between the groups at 3 (adjusted- $P=0.002$ ), 6 (adjusted- $P=0.001$ ), and 12 (adjusted- $P=0.015$ ) months after the operations. The other parameters were not significantly different between the groups after the operations (adjusted- $P>$ 0.05) (Figs. 3 and 4).

The time trend of the radiological parameters with the significant interaction effects between group and time are reported for each group. The values were significantly changed during the follow-up period in group II but not in group I (Figs. 3 and 4). Specifically, in group II, the changes mostly occurred within the 3 postoperative months. The CA, CAE, SA, and SAE values decreased to $11.73^{\circ}(99.5 \% \mathrm{Cl}: 6.85-16.61$, adjusted- $P$ $<0.001), 19.87^{\circ}(99.5 \% \mathrm{Cl}: 12.32-27.42$, adjusted- $P$ < $0.001), 2.97^{\circ}(99.5 \% \mathrm{Cl}:-0.22-6.16$, adjusted- $P=0.063)$, and 5.50 (99.5\% Cl: $3.41-7.58$, adjusted- $P<0.001)$, respectively. C-ROM and S-ROM values increased to $20.32^{\circ}(99.5 \% \mathrm{Cl}: 11.43-29.20$, adjusted- $P<0.001)$ and $4.46^{\circ}(99.5 \% \mathrm{Cl}: 1.43-7.49$, adjusted- $P<0.001)$. The CAF and SAF values did not significantly change $(P>$ 0.05 ). Preoperatively, the CA was $\leq-10^{\circ}$ (lordosis) in 23 patients, $-10^{\circ}-0^{\circ}$ (hypo-lordosis) in 15 patients and $>$ $0^{\circ}$ (kyphosis) in 8 patients. Postoperatively, 6/8 patients with cervical kyphosis and 11/15 patients with cervical hypo-lordosis had lordotic cervical curvatures, whereas $1 / 23$ patients with lordotic cervical curvature had hypolordotic cervical curvature (preoperative CA, $-16.17^{\circ}$; postoperative 12 months $\left(A,-7.89^{\circ}\right.$ ).

When the mixed effect model was used, the interactions between time and group for the parameters of sagittal balance (C2-SVA and T1S-CA) were also significant $(P=0.017$ and 0.037 , respectively, Figs. 5 and 6). Preoperatively, the C2-SVAs were higher in group II than in group I (adjusted- $P=0.039$ ). The C2-SVAs were markedly decreased during the follow-up period in group II compared with group I (Fig. 5). The C2-SVA was significantly decreased by $10.56 \mathrm{~mm}(99.5 \% \mathrm{Cl}: 2.58$ - 18.55, adjusted- $P=0.002$ ) during 12 months but no significant change was observed in group I (Fig. 5).

Preoperative T1S-CA was significantly higher in group II than in group I (adjusted- $P=0.002$ ). However, the increased $C A$ compensated for the mismatch between T1S and CA, and this finding was more prominent in group II than in group I (Fig. 6). The T1S-CA was significantly decreased by $10.82^{\circ}(99.5 \% \mathrm{Cl}: 3.94-17.70$, adjusted- $P<0.001$ ) in group II during 12 months, but was not in group I. 

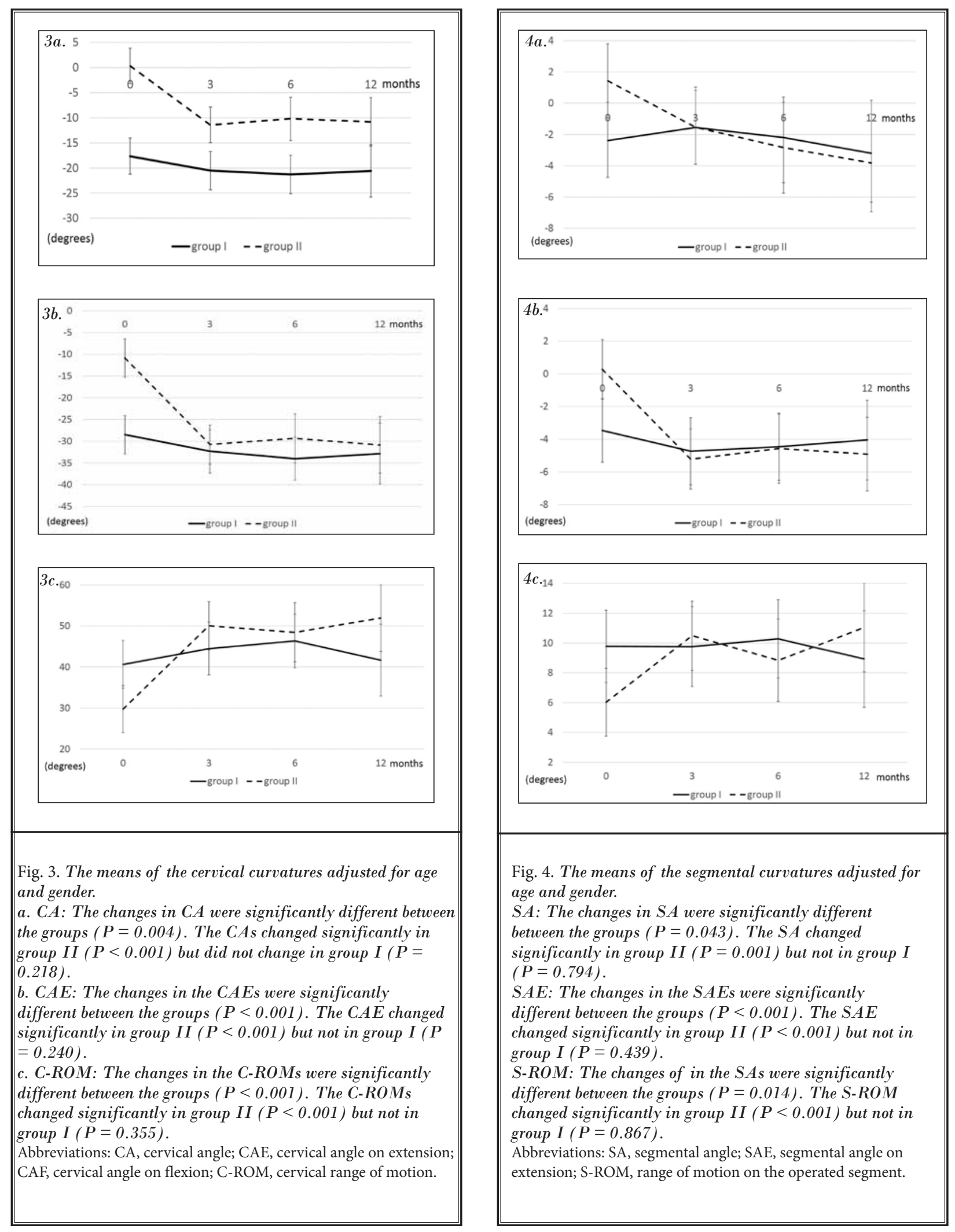

www.painphysicianjournal.com 

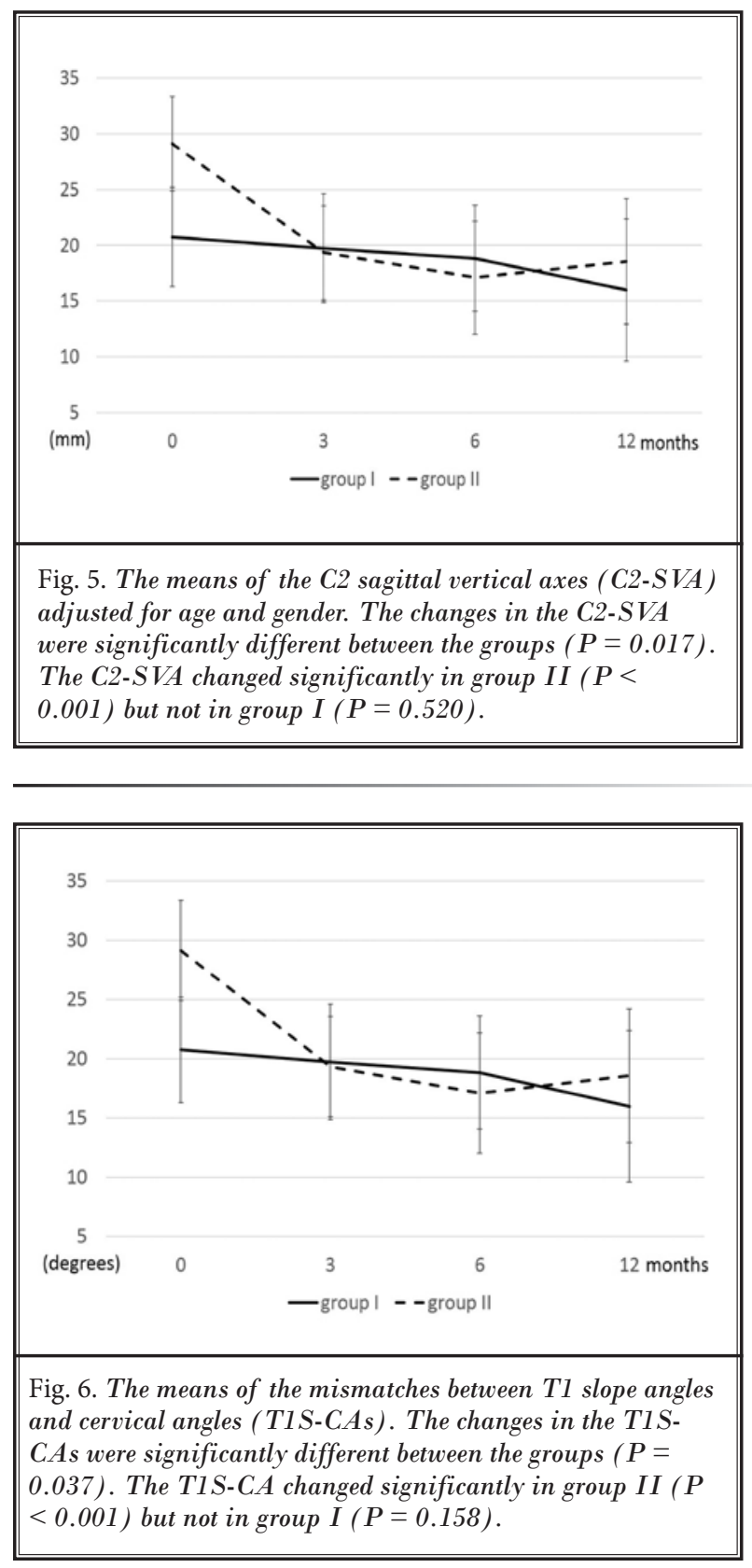

\section{Case}

A 49-year-old woman visited the outpatient clinic due to left arm pain and subjective weakness on left elbow extension, which had begun 2 months ago and was not improved with medication and epidural injections. Spurling's test was positive. The NDI, Arm-VAS, and Neck-VAS were 25/50, 9/10, and 8/10, respectively. Preoperative cervical MRI revealed left C6-7 foraminal soft disc herniation (Fig. 7a). Cervical radiographs revealed kyphotic cervical and segmental curvature (Fig. 7b). P-PECF was performed, and a ruptured disc fragment was removed (Fig. 7c). The clinical symptoms were improved (NDI, 1/50; Arm-VAS, 1/10; neck-VAS, 0/10) at one month after the operation. Cervical radiographs taken at postoperative 3 months revealed improved cervical and segmental curvature and sagittal balance (Fig. 7d).

\section{Discussion}

The present study revealed that clinical improvements were achieved between one and 3 months after the operations without difference between the groups. However, the radiological changes of the cervical spine with time were significantly different between groups. The analysis of the cervical kinematics revealed that there were greater improvements in the cervical and segmental curvatures in the neutral and extension positions in group II than in group I. After the P-PECF operations, lordosis was restored in $17 / 23(74 \%)$ patients in group II. The changes occurred mostly during the first 3 postoperative months in accordance with the improvements in symptoms. Similarly to the cervical curvatures, the cervical sagittal balances were improved after surgery within the first 3 months. The outcomes of the surgeries suggested that the patients, who had developed cervical hypo-lordosis or kyphosis due to pain (group II), could extend their necks more freely because provocative pain was reduced after P-PECF. The patients with cervical lordosis (group I) could move their necks to the extents similar to those of the preoperative states.

\section{Application of P-PECF for Patients with Cervical Lordosis Less than $10^{\circ}$}

Although more evidence is needed, cervical kyphosis may be associated with neck pain and accelerated degenerative processes $(19,24,25,31,32)$. Therefore, correction of preoperative cervical hypo-lordosis and maintenance of the lordotic curvature are important issues in evaluating the outcomes of spinal surgery. $(19,24,25,31,32)$. Cervical hypo-lordosis less than $10^{\circ}$ has been reported to be a risk factor for the progression to cervical kyphosis after open foraminotomy $(2,3)$. Although P-PECF is a minimally invasive surgical technique, its application in patients with decreased cervical lordosis may be controversial $(2,3,6)$. Approximately $1 / 3$ to $1 / 2$ of facet joints are typically violated during open foraminotomy procedures (2), whereas less than $10 \%$ of facet joints are removed during P-PECFs (6). Therefore, 

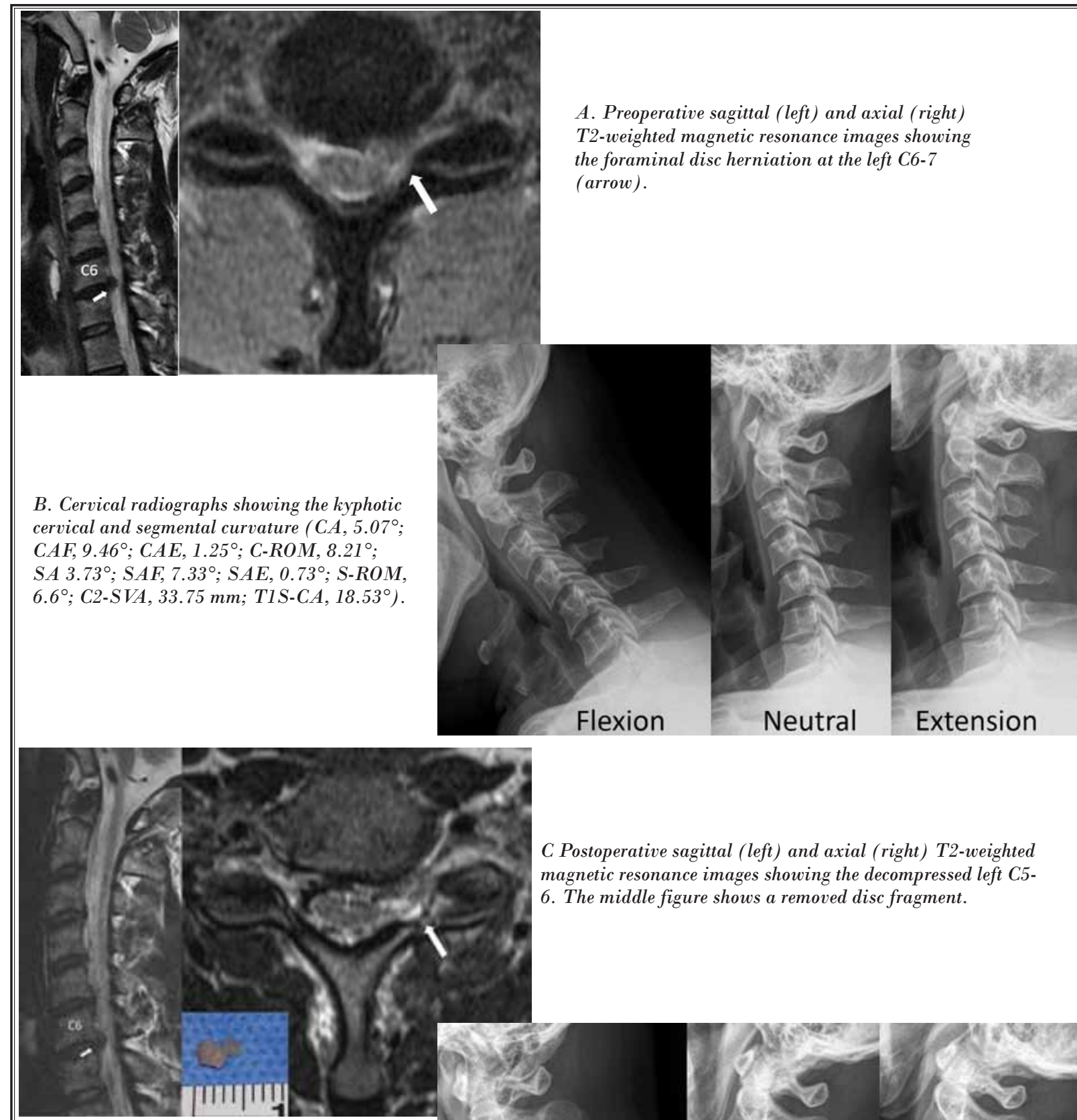

C Postoperative sagittal (left) and axial (right) T2-weighted magnetic resonance images showing the decompressed left $\mathrm{C5}$ 6. The middle figure shows a removed disc fragment.

D. After the operation, the cervical and segmental curvatures were reversed to lordotic curvatures $\left(C A,-16.26^{\circ} ; C A F\right.$, $6.25^{\circ} ; \mathrm{CAE},-22.45^{\circ} ; \mathrm{SA},-0.53^{\circ} ; \mathrm{SAF}$, $2.16^{\circ} ; \mathrm{SAE},-1.37^{\circ} ; \mathrm{C}-\mathrm{ROM}, 28.7^{\circ} ; \mathrm{C} 2$ $\left.S V A, 15.13 \mathrm{~mm} ; \mathrm{T} 1 \mathrm{~S}-\mathrm{CA},-2.8^{\circ}\right)$.

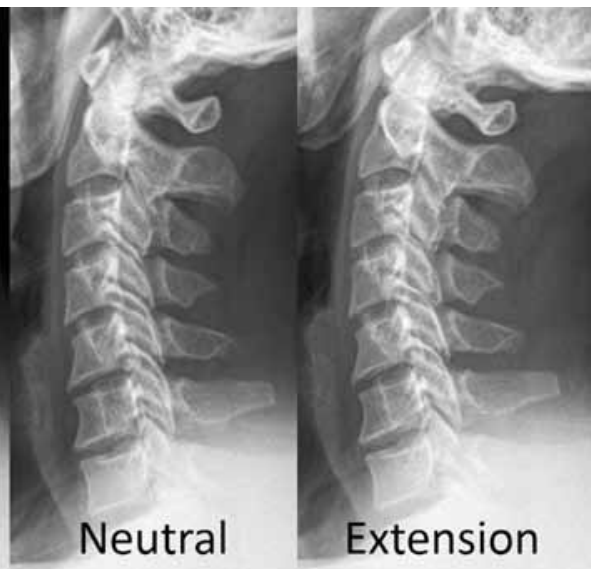

Fig 7. Case. 
the influence of surgery-related injuries associated with P-PECF to the cervical curvature may be different than that of open foraminotomy $(2,6)$.

In the present study, the patients' neck extensions were improved after the operations as clinically demonstrated by the disappearance of a positive Spurling's test $(6,15)$. Improvements in cervical curvature toward lordosis were more marked in the patients with cervical lordosis less than $10^{\circ}$ (group II) than in the patients with cervical lordosis more than $10^{\circ}$ (group I) (6). Although we were unable to provide an exact mechanism for these radiological changes, we hypothesize that the preoperative cervical hypo-lordosis or kyphosis was not a structural change but a functional change in reaction to radicular pain (33), and the successful alleviation of the pain might have restored the lordosis. Similar findings have been observed in patients with lumbar sciatic trunk lists in the previous study (30). Therefore, the postoperative changes were not direct effects of surgery but were secondary effects of reduced pain as demonstrated by the disappearance of a positive Spurling's test.

\section{Limitations}

This study was retrospective in design, and the inherent selection bias and limited statistical power should be considered. Moreover, all the patients did not undergo serial radiographs during the follow-up period. A larger prospective study is required to identify prognostic factors related to the recovery of the cervical lordosis. Secondly, although we demonstrated that functional cervical curvature may change with decreased pain, the differentiation between structural and functional curvature was not simple. According to previous reports, cervical deformity can be defined as a C2-SVA greater than $4 \mathrm{~cm}$ or cervical kyphosis greater than 10 degrees (25). In the present study, the C2-SVAs were greater than $4 \mathrm{~cm}$ in 6 patients and changed to less than $4 \mathrm{~cm}$ in 5 patients after surgery. In 2 patients, cervical kyphosis greater than $10^{\circ}$ was observed, but this kyphosis was reversed to lordosis greater than $10^{\circ}$ and kyphosis of $1.07^{\circ}$, respectively. Despite the cervical curvature that met the previously established criteria for cervical deformity, these patients were not classified as having cervical deformities because instrumented corrections were not necessary (25). Lastly, surgical injury at a facet joint and musculature may counteract to the indirectly positive effects on cervical curvature that are obtained by the alleviation of pain. Long-term follow-up observations of a large number of patients are required to identify the trade-off between the natural return of curvature and the aggravation of the curvature due to of surgical trauma. Nonetheless, the present study demonstrated that cervical hypo-lordosis or kyphosis may be spontaneously reversed with decreased pain and muscle spasms $(6,15)$ when there is minimal degeneration of the disc and facet joint.

\section{Conclusions}

Cervical hypo-lordosis of less than $10^{\circ}$ may not be a contra-indication for P-PECF when the change in the cervical curvature is a functional change caused by pain. If degenerations at the disc and facet joint are minimal, anticipating the natural return of the cervical curvature with a minimally invasive surgical technique and deferring instrumented correction may be an alternative option for selected patients. However, a larger prospective study is required to identify prognostic factors.

\section{References}

1. O'Toole JE, Sheikh H, Eichholz KM, Fessler RG, Perez-Cruet MJ. Endoscopic posterior cervical foraminotomy and discectomy. Neurosurg Clin N Am 2006; 17:411-422.

2. Jagannathan J, Sherman JH, Szabo T, Shaffrey $\mathrm{Cl}$, Jane JA. The posterior cervical foraminotomy in the treatment of cervical disc/osteophyte disease: A single-surgeon experience with a minimum of 5 years' clinical and radiographic follow-up. J Neurosurg Spine 2009; 10:347-356.

3. Fehlings MG, Gray RJ. Posterior cervical foraminotomy for the treatment of cervical radiculopathy. J Neurosurg Spine 2009; 10:343-344; author reply: 344-346.

4. Kim KT, Kim YB. Comparison between open procedure and tubular retractor assisted procedure for cervical radiculopathy: Results of a randomized controlled study. J Korean Med Sci 2009; 24:649-653.

5. Kim CH, Kim KT, Chung CK, Park SB, Yang SH, Kim SM, Sung JK. Minimally invasive cervical foraminotomy and diskectomy for laterally located soft disk herniation. Eur Spine J 2015; 24:3005-3012.

6. Kim CH, Shin $\mathrm{KH}$, Chung CK, Park SB, Kim $\mathrm{JH}$. Changes in cervical sagittal alignment after single-level posterior percutaneous endoscopic cervical diskectomy. Global Spine ] 2015; 5:31-38.

7. Birkenmaier C, Komp M, Leu HF, Wegener $\mathrm{B}$, Ruetten $\mathrm{S}$. The current state of endoscopic disc surgery: Review of controlled studies comparing full-endoscopic procedures for disc herniations to standard procedures. Pain Physician 2013; 16:335-344.

8. Engel A, King W, MacVicar J; Standards Division of the International Spine Intervention Society. The effectiveness and risks of fluoroscopically guided cervical transforaminal injections of steroids: A 
systematic review with comprehensive analysis of the published data. Pain Med 2014; 15:386-402.

9. Richards O, Choi D, Timothy J. Cervical arthroplasty: The beginning, the middle, the end? Br J Neurosurg 2012; 26:2-6.

10. Lee SE, Chung CK, Jahng TA. Early development and progression of heterotopic ossification in cervical total disc replacement. J Neurosurg Spine 2012; 16:31-36.

11. Cho SK, Riew KD. Adjacent segment disease following cervical spine surgery. J Am Acad Orthop Surg 2013; 21:3-11.

12. Ruetten S, Komp M, Merk H, Godolias G. Full-endoscopic cervical posterior foraminotomy for the operation of lateral disc herniations using $5.9-\mathrm{mm}$ endoscopes: A prospective, randomized, controlled study. Spine (Phila Pa 1976) 2008; 33:940-948.

13. Ruetten S, Komp M, Merk H, Godolias G. A new full-endoscopic technique for cervical posterior foraminotomy in the treatment of lateral disc herniations using 6.9- $\mathrm{mm}$ endoscopes: Prospective 2-year results of 87 patients. Minim Invasive Neurosurg 2007; 50:219-226.

14. Yang JS, Chu L, Chen L, Chen F, Ke ZY, Deng ZL. Anterior or posterior approach of full-endoscopic cervical discectomy for cervical intervertebral disc herniation? A comparative cohort study. Spine (Phila Pa 1976) 2014; 39:1743-1750.

15. Tong HC, Haig AJ, Yamakawa K. The Spurling test and cervical radiculopathy. Spine (Phila Pa 1976) 2002; 27:156-159.

16. Kim CH, Chung CK, Kim HJ, Jahng TA, Kim DG. Early outcome of posterior cervical endoscopic discectomy: An alternative treatment choice for physically/ socially active patients. J Korean Med Sci 2009; 24:302-306.

17. Pfirrmann CW, Metzdorf A, Zanetti M, Hodler J, Boos N. Magnetic resonance classification of lumbar intervertebral disc degeneration. Spine (Phila Pa 1976) 2001; 26:1873-1878.
18. Park MS, Lee YB, Moon SH, Lee HM Kim TH, Oh JB, Riew KD. Facet joint degeneration of the cervical spine: $A$ computed tomographic analysis of 320 patients. Spine (Phila Pa 1976) 2014; 39:E713-E718.

19. Skovrlj B, Gologorsky Y, Haque R, Fessler RG, Qureshi SA. Complications, outcomes, and need for fusion after minimally invasive posterior cervical foraminotomy and microdiscectomy. Spine J 2014; 14:2405-2411.

20. Lee H, Nicholson LL, Adams RD, Maher CG, Halaki M, Bae SS. Development and psychometric testing of Korean language versions of 4 neck pain and disability questionnaires. Spine (Phila $\mathrm{Pa}$ 1976) 2006; 31:1841-1845.

21. Park MS, Kelly MP, Lee DH, Min WK Rahman RK, Riew KD. Sagittal alignment as a predictor of clinical adjacent segment pathology requiring surgery after anterior cervical arthrodesis. Spine J 2014; 14:1228-1234.

22. Kim B, Yoon do H, Ha Y, Yi S, Shin DA, Lee CK, Lee N, Kim KN. Relationship between $\mathrm{T}_{1}$ slope and loss of lordosis after laminoplasty in patients with cervical ossification of the posterior longitudinal ligament. Spine J 2016; 16:219-225.

23. Jun HS, Kim JH, Ahn JH, Chang IB, Song $J H$, Kim TH, Park MS, Kim YC, Kim SW, Oh JK. Tr slope and degenerative cervical spondylolisthesis. Spine (Phila Pa 1976) 2015; 40:E220-E226.

24. Tang JA, Scheer JK, Smith JS, Deviren V, Bess S, Hart RA, Lafage V, Shaffrey $\mathrm{Cl}$, Schwab F, Ames CP, International Spine Study Group. The impact of standing regional cervical sagittal alignment on outcomes in posterior cervical fusion surgery. Neurosurgery 2012; 71:662-669; discussion 669

25. Iyer S, Nemani VM, Nguyen J, Elysee J, Burapachaisri A, Ames CP, Kim HJ. Impact of cervical sagittal alignment parameters on neck disability. Spine (Phila Pa 1976) 2016; 41:371-377.
26. Hyun SJ, Kim KJ, Jahng TA, Kim HJ. Relationship between $\mathrm{T}_{1}$ slope and cervical alignment following multi-level posterior cervical fusion surgery: Impact of T1 slope minus cervical lordosis. Spine (Phila Pa 1976) 2016; 41:396-402.

27. Lee SH, Son ES, Seo EM, Suk KS, Kim KT. Factors determining cervical spine sagittal balance in asymptomatic adults: Correlation with spinopelvic balance and thoracic inlet alignment. Spine J 2015; 15:705-712.

28. Kim CH, Chung CK, Hong HS, Kim EH, Kim MJ, Park BJ. Validation of a simple computerized tool for measuring spinal and pelvic parameters. J Neurosurg Spine 2012; 16:154-162.

29. Carreon LY, Glassman SD, Campbell MJ, Anderson PA. Neck Disability Index, short form-36 physical component summary, and pain scales for neck and arm pain: The minimum clinically important difference and substantial clinical benefit after cervical spine fusion. Spine J 2010; 10:469-474.

30. Kim $\mathrm{RH}$, Kim $\mathrm{CH}$, Choi Y, Hong HS, Park SB, Yang SH, Kim SM, Chung CK. The incidence and risk factors for lumbar or sciatic scoliosis in lumbar disc herniation and the outcomes after percutaneous endoscopic discectomy. Pain Physician 2015; 18:555-564.

31. Ryu WH, Kowalczyk I, Duggal N. Longterm kinematic analysis of cervical spine after single-level implantation of Bryan cervical disc prosthesis. Spine J 2013; 13:628-634.

32. Kim CH, Chung CK, Hahn S. Autologous iliac bone graft with anterior plating is advantageous over the standalone cage for segmental lordosis in single-level cervical disc disease. Neurosurgery 2013; 72:257-265; discussion 266.

33. Rudolfsson T, Bjorklund M, Djupsjobacka M. Range of motion in the upper and lower cervical spine in people with chronic neck pain. Man Ther 2012; 17:53-59. 
